\title{
Characterization of Carbon Films Prepared from Polybenzoxazine Films
}

\author{
Yoshiki Takahashi, Tsubasa Osawa, Yuzi Shibayama, Akihiko Matsumoto, and Tsutomu Takeichi \\ Department of Environmental and Life Sciences, Toyohashi University of Technology, \\ 1-1 Hibarigaoka, Tempaku-cho, Toyohashi 441-8580, Japan \\ takeichi@ens.tut.ac.jp
}

\begin{abstract}
Two types of polybenzoxazine films, PBa and PPd, that were prepared by the thermal cure of benzoxazines, $\mathrm{Ba}$ and $\mathrm{Pd}$, were carbonized at temperature-controlled condition, and the effect of the chemical structure of the polybenzoxazines on carbonization was examined by comparing with the carbonization behavior of polyimide film. X-ray diffraction and X-ray photoelectron spectra measurements showed that the carbon films prepared by heat treatment of rigid polybenzoxazine, PPd, at $900{ }^{\circ} \mathrm{C}$ and $1000{ }^{\circ} \mathrm{C}$ were the most graphitized. Micrographitic structure was confirmed by transmission electron microscope observation for the carbonized films of PBa and PPd at $1000{ }^{\circ} \mathrm{C}$.
\end{abstract}

Keywords: polybenzoxazine, phenolic resin, carbonization

\section{Introduction}

Carbonization process of polymer strongly depends on the molecular structure and the higher ordered structure of the polymer. There have been various reports on the carbonization and graphitization of aromatic polymers such as polyoxadiazole (POD) $[1,2]$ and polyimide (PI) films. It was found that carbonization and graphitization of POD and PI with planar and rigid structure take place easily [3]. Especially, carbonization and graphitization of PI were extensively studied because of the molecular design flexibility of PI. The effects of chemical structure of PI [4], cold-drawing of PI film [5-7], and constraint during imidization of poly(amide acid) [8] on carbonization and graphitization have been extensively reported on the Kapton type PI, PI(PMDA/ODA) [9], and other PI films [10-14]. It was also revealed that carbonization of PI films give microporous carbon films by thermally treating PI films at $700-900{ }^{\circ} \mathrm{C}[15,16]$. Furthermore, it was reported that the thermal degradation of poly (urethane-imide) gave porous PI film [17-19] which further leads porous carbon film [20,21].

On the contrary, it is known that the carbonization and graphitization of phenolic resin having complex three-dimensional structure are rather difficult [22, 23]. Recently, polybenzoxazines prepared by the ring-opening polymerization of cyclic monomers, benzoxazines, are recognized as a new type of phenolic resin [24]. It is known that polybenzoxazine has good flame retardance and high char yield, however, there is no study on the carbonization of polybenzoxazine.

In this study, carbonization of polybenzoxazine films prepared by two types of benzoxazines, $\mathrm{Pd}$ and $\mathrm{Ba}$, was examined (Fig. 1). The carbonization was of these polybenzoxazine films was compared with that of a typical polyimide, PI (PMDA/ODA) (Fig. 2).

\section{Experimental}

\subsection{Materials}

Aniline, paraformaldehyde and 4,4'-oxydianiline (ODA) were purchased from Wako Pure Chemicals. Bisphenol A and pyromellitic dianhydride (PMDA) were purchased from Kishida Chemicals. Pd was kindly supplied by Shikoku Chemicals, and purified by washing with $2.0 \mathrm{~mol} / \mathrm{L}$ of aqueous sodium hydroxide and water. $\mathrm{Ba}$ was synthesized from bisphenol A, aniline and paraformaldehyde by the conventional solvent-less method for 30 minutes at $120^{\circ} \mathrm{C}$.

\subsection{Preparation of Polybenzoxazine Films}

One gram of benzoxazine, $\mathrm{Ba}$ or $\mathrm{Pd}$, was 


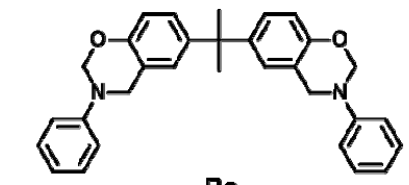

Ba
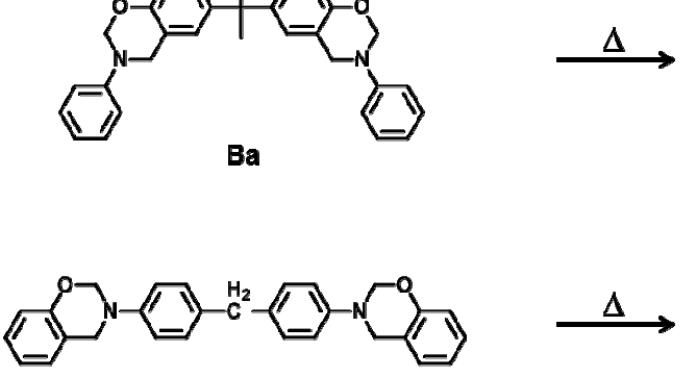

Pd
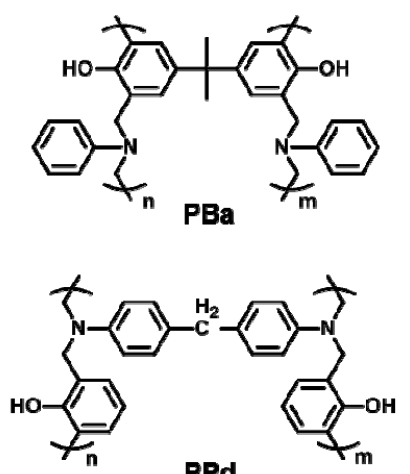

PPd

Fig. 1. Structures of benzoxazines ( $\mathrm{Ba}$ and $\mathrm{Pd}$ ) and polybenzoxazines ( $\mathrm{PBa}$ and $\mathrm{PPd})$.

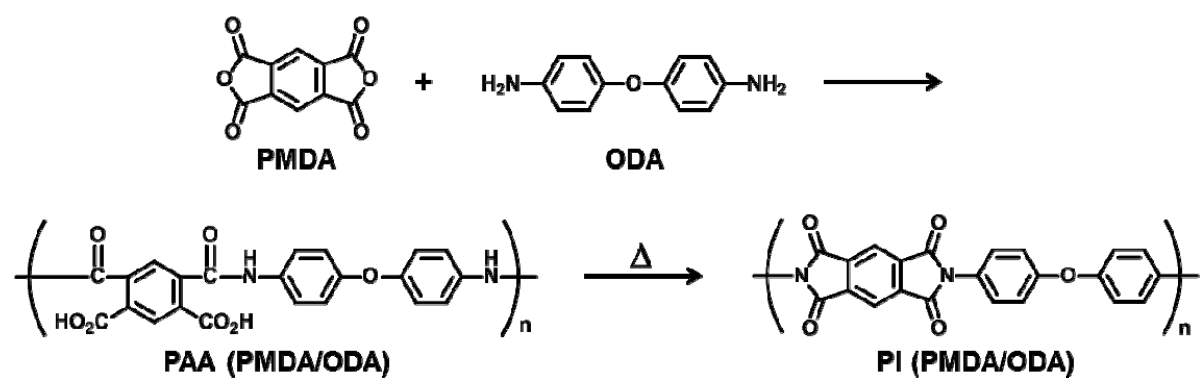

Fig. 2. Preparation of PI(PMDA/ODA).

dissolved into $3.0 \mathrm{ml}$ of THF. The THF solution was cast on a silanized glass plate and heated at $60{ }^{\circ} \mathrm{C}$ for $16 \mathrm{~h}$, and then at $100{ }^{\circ} \mathrm{C}, 160{ }^{\circ} \mathrm{C}, 200{ }^{\circ} \mathrm{C}$, and $240{ }^{\circ} \mathrm{C}$ for $1 \mathrm{~h}$ each.

\subsection{Preparation of PI Films}

ODA and PMDA were reacted in $N$-methyl-2-pyrrolidinone (NMP) under nitrogen for $4 \mathrm{~h}$ at room temperature, giving viscous poly(amide acid) (PAA) solution, which was cast on a glass plate and heated at $50{ }^{\circ} \mathrm{C}$ for $16 \mathrm{~h}$, and then at $100{ }^{\circ} \mathrm{C}, 200{ }^{\circ} \mathrm{C}, 300{ }^{\circ} \mathrm{C}$, and $350{ }^{\circ} \mathrm{C}$ for $1 \mathrm{~h}$ each, affording yellow PI film with thickness around 50 $\mu \mathrm{m}$.

\subsection{Preparation of Carbon Films}

Polymer film was cut into $50 \mathrm{~mm} \times 50 \mathrm{~mm}$ and sandwiched between porous alumina plates, and then heated at $800{ }^{\circ} \mathrm{C}, 900{ }^{\circ} \mathrm{C}$, and $1000^{\circ} \mathrm{C}$ for $1 \mathrm{~h}$ each under nitrogen atmosphere at a heating rate of $10{ }^{\circ} \mathrm{C} / \mathrm{min}$.

\subsection{Measurements}

${ }^{1} \mathrm{H}$ NMR spectra were recorded on a JEOL JNM-EC400 (400 MHz) at room temperature. Fourier transform-infrared (FT-IR) spectra were recorded on a JASCO FT-IR420 spectrometer equipped with an ATR 450-s unit. Differential scanning calorimetry (DSC) was measured on a Rigaku DSC8230 at a heating rate of $10{ }^{\circ} \mathrm{C} / \mathrm{min}$ under nitrogen atmosphere. Thermogravimetric analyses (TGA) were measured on a Rigaku TG8120 at a heating rate of $5{ }^{\circ} \mathrm{C} / \mathrm{min}$ under argon atmosphere. X-ray diffraction patterns (XRD) were recorded on a Rigaku RINT2000 and RINT2200 using $\mathrm{Cu}-\mathrm{K}_{\alpha}$ radiation. X-ray photoelectron spectra (XPS) were measured by a ULVAC-PHI Quantera SXM-CL. Transmission electron microscope (TEM) observations were conducted on a JEOL JEM-2100F. Nitrogen adsorption isotherms were measured by an automatic adsorption apparatus (Quantachrome AUTOSORB-1) at $-196^{\circ} \mathrm{C}$.

\section{Results and Discussion}

3.1. Carbonization of Polybenzoxazine and Polyimide Films

Carbonization of PI, PBa, and PPd films gave carbon films with silver metallic luster, which suggests that all the carbon films were graphitized to some degree.

Carbon yield and dimensions of carbon films are shown as Table 1. Yields of carbon films were in the 
order of $\mathrm{PI}>\mathrm{PPd}>\mathrm{PBa}$, which corresponds to the char yield determined by TGA measurements of polymer films (Table 2). Aromatic content was calculated to be $66 \%$ for PPd, $62 \%$ for $\mathrm{PBa}$, and $52 \%$ for PI, which corresponds to the different thermal decomposition behavior between polybenzoxazines and polyimides.

It was also observed that PI film did not shrink so much during carbonization in the direction of thickness as compared with PBa and PPd. This was considered to be due to the high in-plane orientation of PI film.

Table 1. Dimensions and carbon yields of carbon films.

\begin{tabular}{crccc}
\hline \multicolumn{2}{c}{ Polymer } & $\begin{array}{c}\text { Length } \\
(\%)\end{array}$ & $\begin{array}{c}\text { Thickness } \\
(\%)\end{array}$ & $\begin{array}{c}\text { Yield } \\
(\%)\end{array}$ \\
\hline \multirow{4}{*}{$\mathrm{PI}$} & $800^{\circ} \mathrm{C}$ & 77 & 94 & 57 \\
& $900^{\circ} \mathrm{C}$ & 76 & 94 & 53 \\
& $1000^{\circ} \mathrm{C}$ & 76 & 93 & 47 \\
\hline \multirow{4}{*}{$\mathrm{PBa}$} & $800^{\circ} \mathrm{C}$ & 74 & 65 & 34 \\
& $900^{\circ} \mathrm{C}$ & 72 & 60 & 30 \\
& $1000^{\circ} \mathrm{C}$ & 71 & 57 & 26 \\
\hline \multirow{4}{*}{$\mathrm{PPd}$} & $800^{\circ} \mathrm{C}$ & 75 & 74 & 48 \\
& $900^{\circ} \mathrm{C}$ & 74 & 73 & 45 \\
& $1000^{\circ} \mathrm{C}$ & 74 & 70 & 41 \\
\hline
\end{tabular}

Table 2. Char yields of polymer films on TGA measurements at a heating rate of $5{ }^{\circ} \mathrm{C} / \mathrm{min}$ under argon atmosphere.

\begin{tabular}{cccc}
\hline \multirow{2}{*}{ Polymer } & \multicolumn{3}{c}{ Char yield (\%) } \\
\cline { 2 - 4 } & $800{ }^{\circ} \mathrm{C}$ & $900{ }^{\circ} \mathrm{C}$ & $1000^{\circ} \mathrm{C}$ \\
\hline $\mathrm{PI}$ & 52 & 45 & 37 \\
$\mathrm{PBa}$ & 24 & 24 & 15 \\
$\mathrm{PPd}$ & 47 & 38 & 30 \\
\hline
\end{tabular}

\subsection{XRD of Carbon Films}

XRD patterns of carbon films are shown in Fig. 3. XRD of the carbon films showed peaks attributable to (002) and (101) at $2 \theta=25^{\circ}(\mathrm{d}=0.35 \mathrm{~nm})$ and $44^{\circ}$ $(d=0.29 \mathrm{~nm})$, respectively. The diffraction peaks of the (002) plane was observed in the diffraction patterns of all carbon films, but the peak was broad, suggesting that all carbon films include the turbostratic structures and/or micrographite structure.

Figure 4 shows the change of the intensity of the
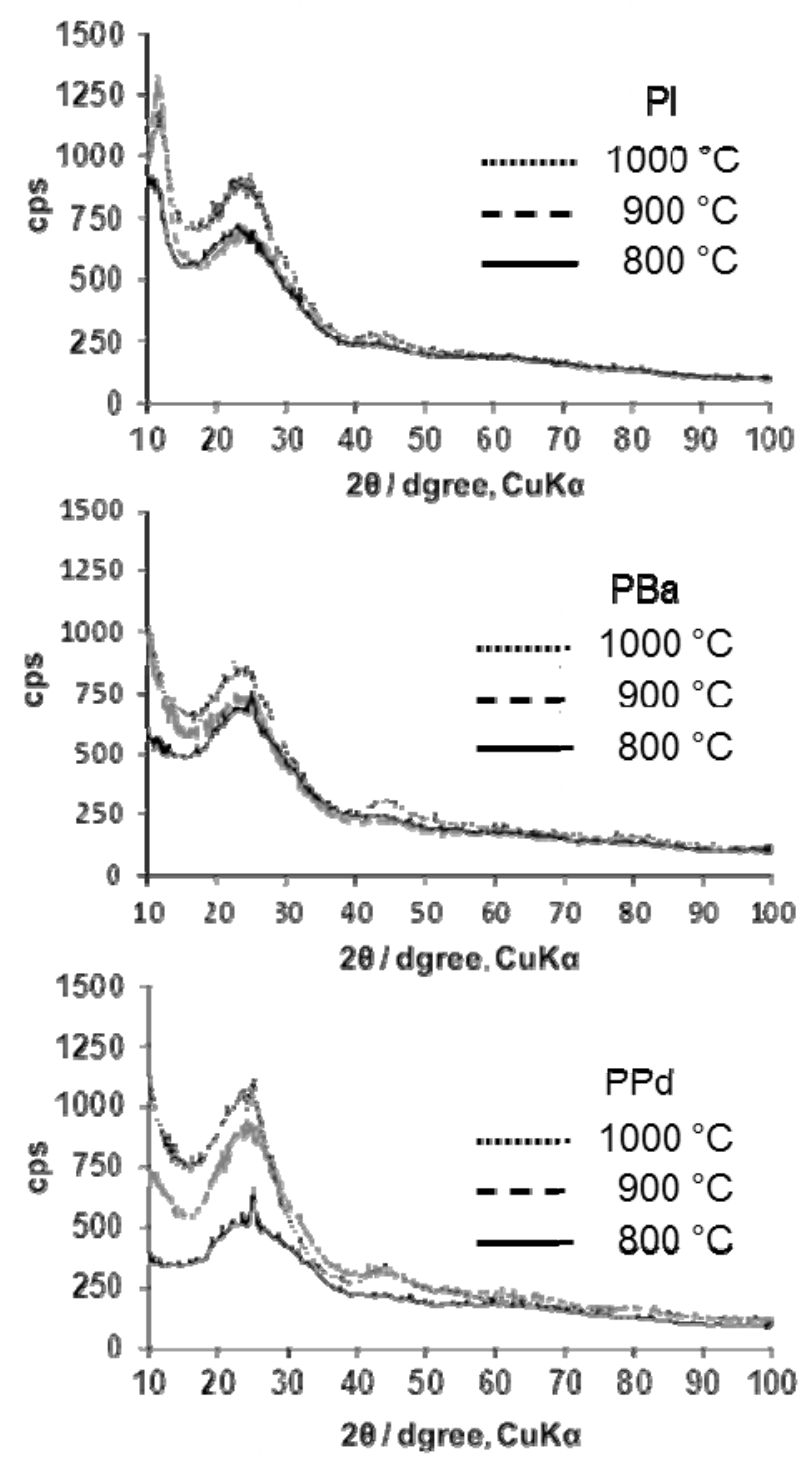

Fig. 3. XRD patterns of carbon films from PBa, PPd, and PI.

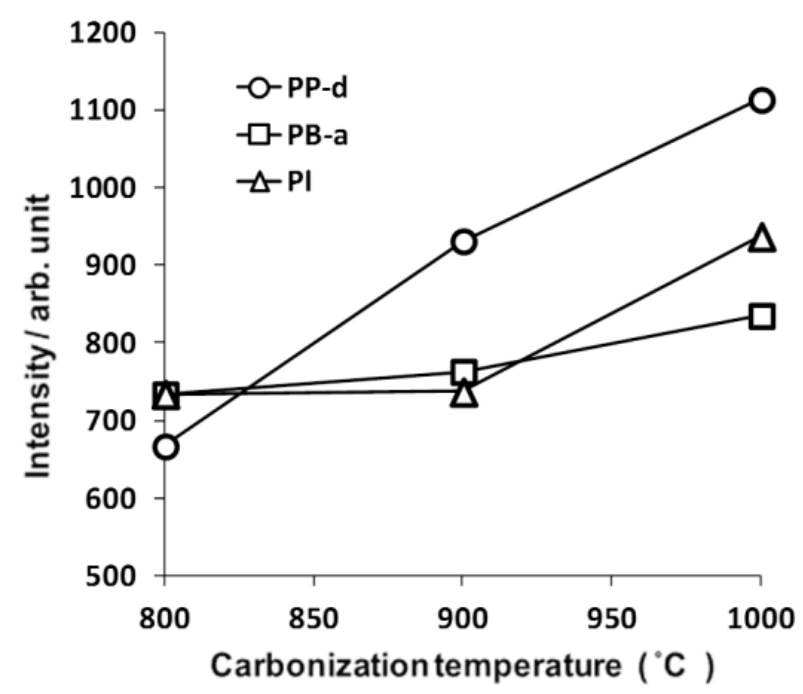

Fig. 4. Change in the diffraction intensity of (002) by carbonization temperature. 

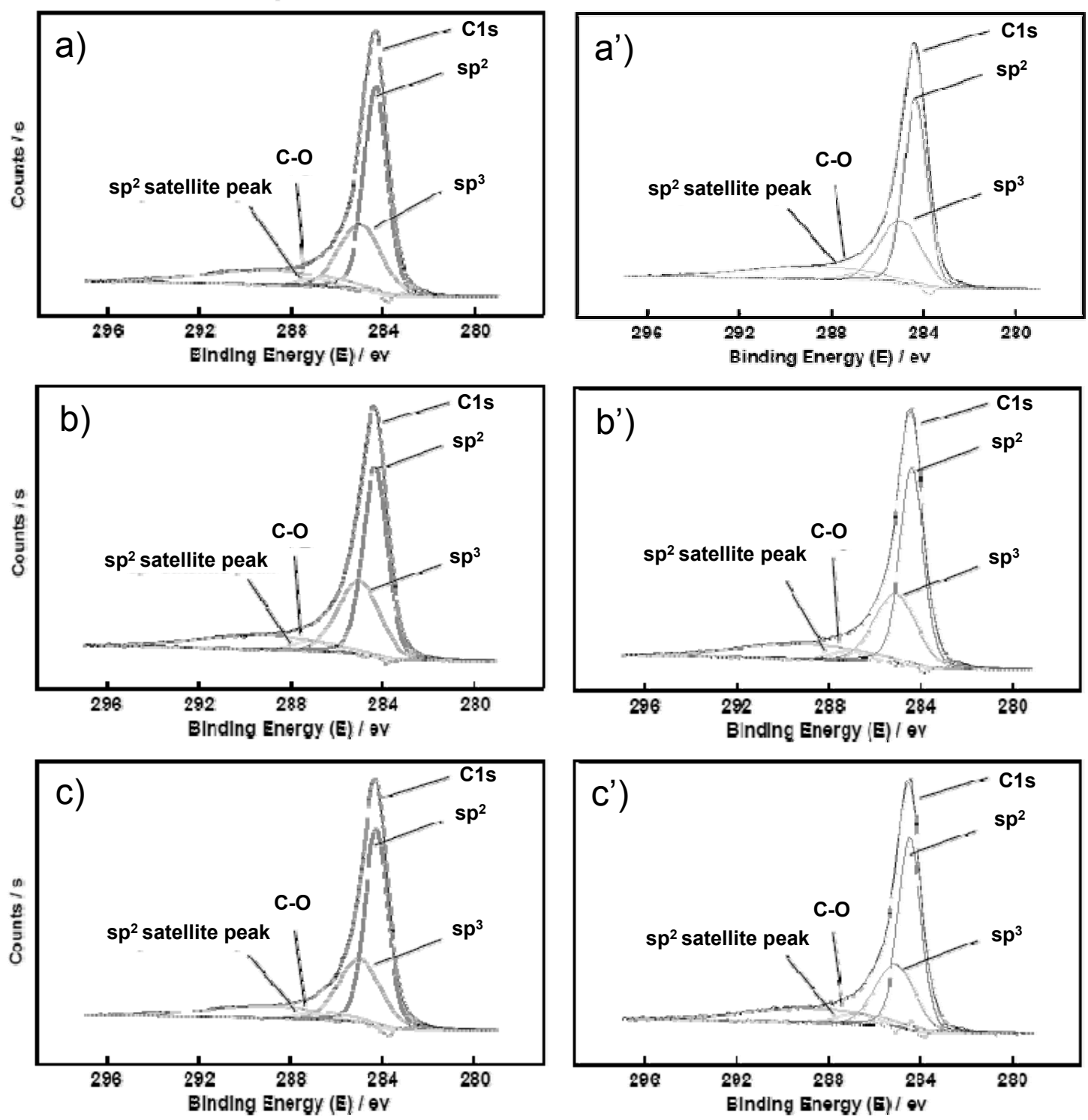

Fig. 5. XPS of carbon films. Surface: a) PI, b) PBa, c) PPd, etched part: a') PI, b') PBa, c') PPd.

diffraction peak of the (002) plane of each carbon film prepared at different carbonization temperature. The intensity of the (002) plane increased with increasing the carbonization temperature for all the carbon films. Therefore, graphitization would develop with increasing carbonization temperature. Among the carbon films examined, the diffraction intensity of the (002) plane of carbon film of PPd was the highest. This suggests that development of graphitization is most pronounced for PPd that have a rigid structure.

\subsection{XPS of Carbon Films}

XPS measurements of the carbon films were conducted on the surface and also on the inner part being etched for $0.5 \mathrm{~nm}$ from the surface to estimate the graphitization ratio of the carbon films. XPS of carbon films are shown in Fig. 5. Observed peaks of carbon was accurately fitted by four waveforms, $\mathrm{sp}^{2}$ hybrid orbital $(284.3 \mathrm{eV}), \mathrm{sp}^{3}$ hybrid orbital (285 $\mathrm{eV}), \mathrm{sp}^{2}$ satellite peak $(287 \mathrm{eV})$, and $1 \mathrm{~S}$ orbital of $\mathrm{C}-\mathrm{O}(289 \mathrm{eV})$. It is considered that $\mathrm{sp}^{2}$ satellite peak is based on $\pi-\pi^{*}$ electron transition.

Graphitization ratios of the carbon films were estimated by the ratio of $\mathrm{sp}^{2}$ hybrid orbital among all the peaks except $1 \mathrm{~S}$ orbital of $\mathrm{C}-\mathrm{O}$ and $\mathrm{sp}^{2}$ satellite peak, and summarized in Table 3. Graphitization ratios on the surface and the etched part of PPd were higher than those of $\mathrm{PBa}$ and PI. There results suggest that graphitization of PPd is even more significant than PI, which is known as easily graphitizable polymer, and considered to be very interesting. 
Table 3. Ratios of graphitization of carbon films.

\begin{tabular}{ccccc}
\hline \multirow{2}{*}{ Polymer } & \multicolumn{3}{c}{ Ratio of graphitization (\%) } \\
\cline { 3 - 5 } & & $800^{\circ} \mathrm{C}$ & $900^{\circ} \mathrm{C}$ & $1000^{\circ} \mathrm{C}$ \\
\hline \multirow{2}{*}{$\mathrm{PI}$} & surface & 62 & 64 & 66 \\
& etching & 61 & 61 & 64 \\
\hline \multirow{2}{*}{$\mathrm{PBa}$} & surface & 57 & 64 & 65 \\
& etching & 55 & 57 & 64 \\
\hline \multirow{2}{*}{$\mathrm{PPd}$} & surface & 46 & 65 & 73 \\
& etching & 45 & 63 & 68 \\
\hline
\end{tabular}

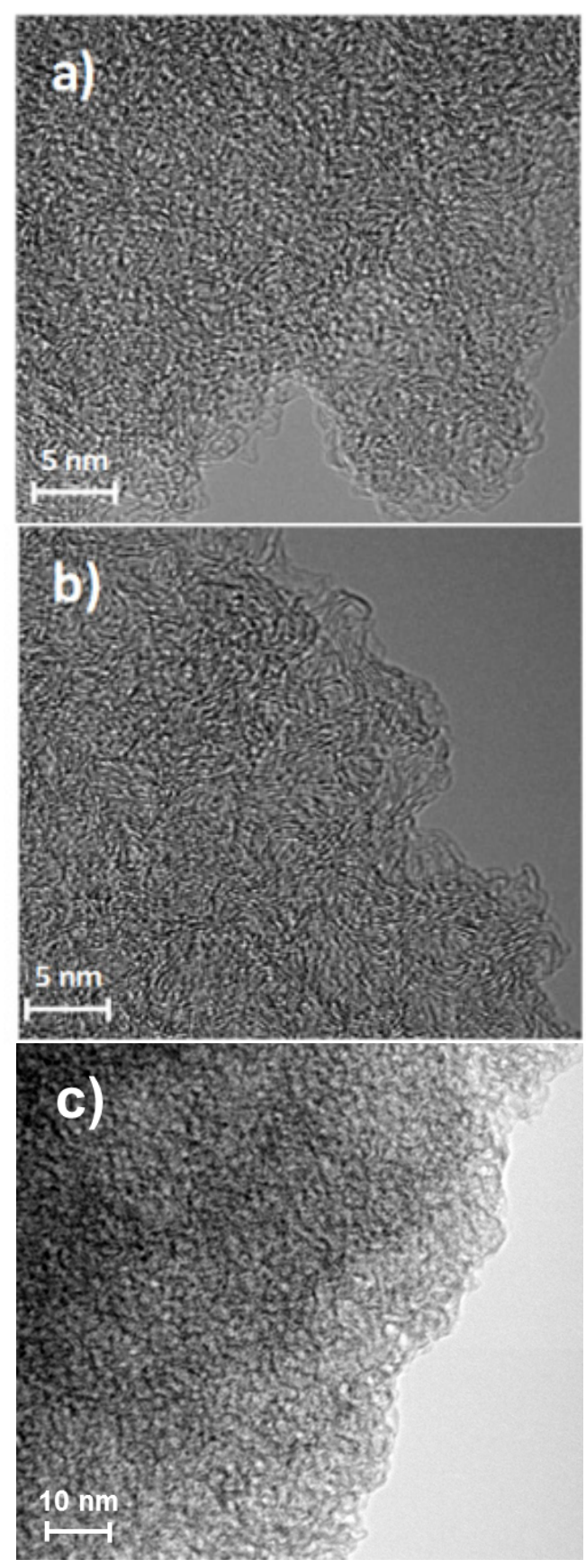

Fig. 6. TEM images of carbon films after carbonization at $1000^{\circ} \mathrm{C}$ for $\left.\left.\left.1 \mathrm{~h}, \mathrm{a}\right) \mathrm{PBa}, \mathrm{b}\right) \mathrm{PPd}, \mathrm{c}\right) \mathrm{PI}$.

\subsection{TEM Observation of Carbon Films}

TEM images of the carbon films prepared by the thermal treatment of $\mathrm{PBa}, \mathrm{PPd}$ and PI at $1000^{\circ} \mathrm{C}$ are shown in Fig. 6. Lattice fringe images of micrographitic structure were observed in the carbon films, indicating that the polymers easily graphitized at $1000^{\circ} \mathrm{C}$.

\subsection{Nitrogen Adsorption Measurements of Carbon Films}

The nitrogen adsorption isotherms of the carbon films of PPd were measured, to characterize porous features of the materials. It has already reported that PI gave microporous carbon films by the thermal decomposition [15, 16]. However, as shown Fig.7, no microporous structure was detected in the carbon films from PPd by the adsorption of $\mathrm{N}_{2}$. The macroporous stuctures decreased with increasing the carbonization temperature for the carbon film of PPd.

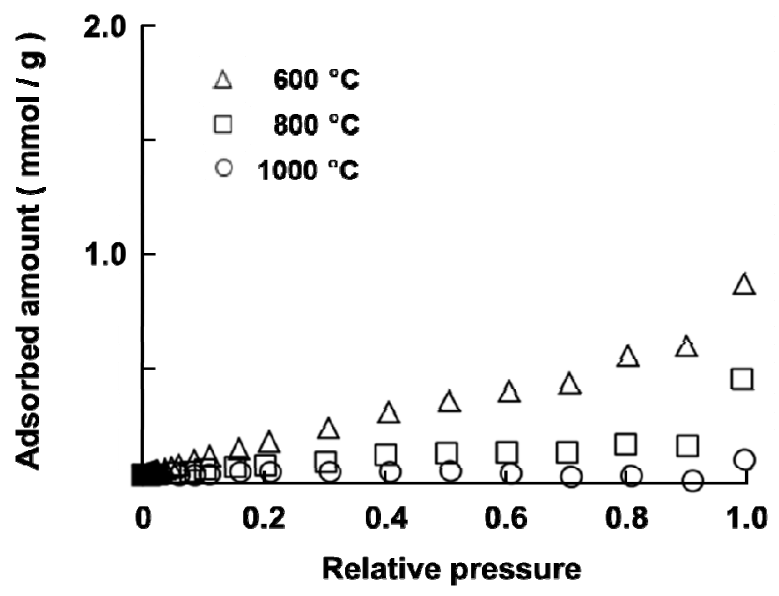

Fig. 7. Nitrogen adsorption isotherms of carbon films of PPd carbonized at different temperature.

\section{Conclusion}

Judging from XRD and XPS measurements, the carbon films prepared by the heat treatment of PPd having a rigid structure at $900{ }^{\circ} \mathrm{C}$ and $1000{ }^{\circ} \mathrm{C}$ were the most graphitized. It is very interesting that PPd is easier to graphitize than PI which is known to be an excellent graphite precursor.

\section{References}

1. M. Murakami and S. Yoshimura, Synth. Met., 18 (1987) 509.

2. M. Murakami, K. Watanabe, and S. Yoshimura, Appl. Phys. Lett., 48 (1986) 1594. 
3. M. Inagaki, T. Takeichi, Y. Hishiyama, and A. Oberlin, Chemistry and Physics of Carbon, 26, (1999) 245.

4. M. Inagaki, T. Ibuki, and T. Takeichi, J. Appl. Polym. Sci., 44 (1992) 521.

5. T. Takeichi, H. Takenoshita, S. Ogura, and M. Inagaki, Chemistry Letters, 4 (1993) 657.

6. T. Takeichi, H. Takenoshita, S. Ogura, and M. Inagaki, J. Appl. Polym. Sci., 54 (1994) 361.

7. T. Takeichi, Y. Kaburagi, Y. Hishiyama, and M. Inagaki, Carbon, 33 (1995) 1621.

8. M. Inagaki, M. Sato, T. Takeichi, A. Yoshida, and Y. Hishiyama, Carbon, 30 (1992) 903.

9. T. Takeichi, Y. Eguchi, Y. Kaburagi, Y. Hishiyama, and M. Inagaki, Carbon, 36 (1998) 117.

10. T. Takeichi, Y. Endo, Y. Kaburagi, Y. Hishiyama, and M. Inagaki, J. Appl. Polym. Sci., 61 (1996) 1571.

11. T. Takeichi, Y. Endo, Y. Kaburagi, Y. Hishiyama, and M. Inagaki, J. Appl. Polym. Sci., 68 (1998) 1613.

12. T. Takeichi, Y. Eguchi, Y. Kaburagi, Y. Hishiyama, and M. Inagaki, Carbon, 37 (1999) 569.

13. T. Takeichi, M. Zuo, and M. Hasegawa, J. Polym. Sci.: Part B: Polym. Phys., 39 (2001) 3011.

14. V. E. Smirnova, I. V. Gofman, T. A. Maritcheva,
V. E. Yudin, K. Eto, T. Takeichi, Y. Kaburagi, and Y. Hishiyama, Carbon, 45 (2007) 839.

$15 \mathrm{~K}$. Tamada, K. Arimatsu, A. Matsumoto, and T. Takeichi, TANSO, [No. 261], (2014) 1.

16. K. Tamada, T. Kobayashi, A. Matsumoto, T. Takeichi, R. Yokota, and J. T. Lin, TANSO, [No. 262], (2014) 63.

17. T. Takeichi, M. Zuo, and A. Ito, High Perform. Polym., 11 (1999) 1.

18. T. Takeichi, Y. Yamazaki, A. Ito, and M. Zuo, J. Photopolym. Sci. Technol., 12 (1999) 203.

19. T. Takeichi and Y. Yamazaki, J. Photopolym. Sci. Technol., 13 (2000) 333.

20. T. Takeichi, Y. Yamazaki, T. Fukui, A. Matsumoto, and M. Inagaki, TANSO, [No. 195], (2000) 388.

21. T. Takeichi, Y. Yamazaki, M. Zuo, A. Ito, A. Matsumoto, and M. Inagaki, Carbon, 39 (2001) 257.

22. S. Yamada and M. Inagaki, Carbon, 9 (1971) 691.

23. S. Ohtani and M. Kimura, "Tansosen-i", Kindai-henshu-sha (1972) p8 (in Japanese).

24. T. Takeichi, T. Kawauchi, and T. Agag, Polym. J., 40 (2008) 1121. 